\title{
Ambient Intelligence for Optimal Manufacturing and Energy Efficiency
}

\author{
David Charles Robinson, David Sanders and Ebrahim Mazharsolook
}

\begin{abstract}
This paper describes research work to create an innovative, and intelligent solution for Energy Efficiency optimisation in manufacturing companies. The solution is based on a novel approach to energy consumption monitoring by introduction of Ambient Intelligence plus extended data sets with Knowledge Management technologies to realise a decision support system as an innovative add-on to currently used Energy Management Systems. As a result of such an innovative monitoring concept, the Energy Efficiency software services are developed as front end of the system. The main aim of the research was to produce a leap forward in energy efficiency by introducing Ambient Intelligence (AmI) aspects into classical energy consumption monitoring in manufacturing SMEs. To achieve this aim, the research envisaged development of an ambient intelligent monitoring system for energy consumption, intended for application in manufacturing companies, to provide comprehensive information about energy use, and knowledge-based support for improvements in energy efficiency. Standard energy consumption data are complemented by information from ambient intelligence systems from both environment-ambient and process ambient, and processed within a service-oriented-architecture based platform. The platform allows for building of different above mentioned energy efficiency software services using the measured and processed data, four of which are selected for the system prototype: (a) Condition-based energy consumption warning, (b) On-line diagnostics of energy related problems, (c) Support to manufacturing process lines installation and ramp-up phase, and (d) Continuous improvement/optimisation of energy efficiency. The services are interactively providing suggestions for appropriate actions for energy problem elimination and energy efficiency increase. The system functionalities were trialled in a manufacturing company that produces mooring chains for the offshore oil and gas industry, which is very energy intensive.

This paper is based on work done during the AmI-MoSES project, which was partly funded by the European Commission in the scope of the Information and Communication Technologies (ICT) programme - ICT for Sustainable Growth.
\end{abstract}

Keywords: Ambient Intelligence, Sensors, Energy Efficiency, Knowledge Management

\section{Introduction}

This research addresses two of the most critical problems in energy management in industrial production technologies: how to efficiently and promptly acquire and provide information online for optimising energy consumption; and how to effectively use such knowledge to support decision making. This research was inspired by the need for industry to have effective tools for energy efficiency and that opportunities for industry to take up Energy Efficiency measures are mostly not carried out [1].

The research combined Ambient Intelligence (AmI) and Knowledge Management (KM) technologies $[2,3]$. AmI technology involved new uses of sensors including wireless intelligent sensor networks, to measure environment parameters and conditions as well as to process performance and behaviour aspects, such as material flow using smart tags in highly flexible manufacturing or temperature distribution over machines $[4,5,6,7]$. The information obtained could be correlated with standard energy consumption data to monitor energy efficiency and identify problems [8]. The new approach can provide effective ways to collect more information to give a new insight into energy consumption within a manufacturing system.

The paper describes a case study involving energy intensive processes that addressed different manufacturing concepts, and involved the manufacture of mooring chains for off-shore platforms. The system was developed to support online detection of energy efficiency problems.

The general concept is presented in Figure 1. 


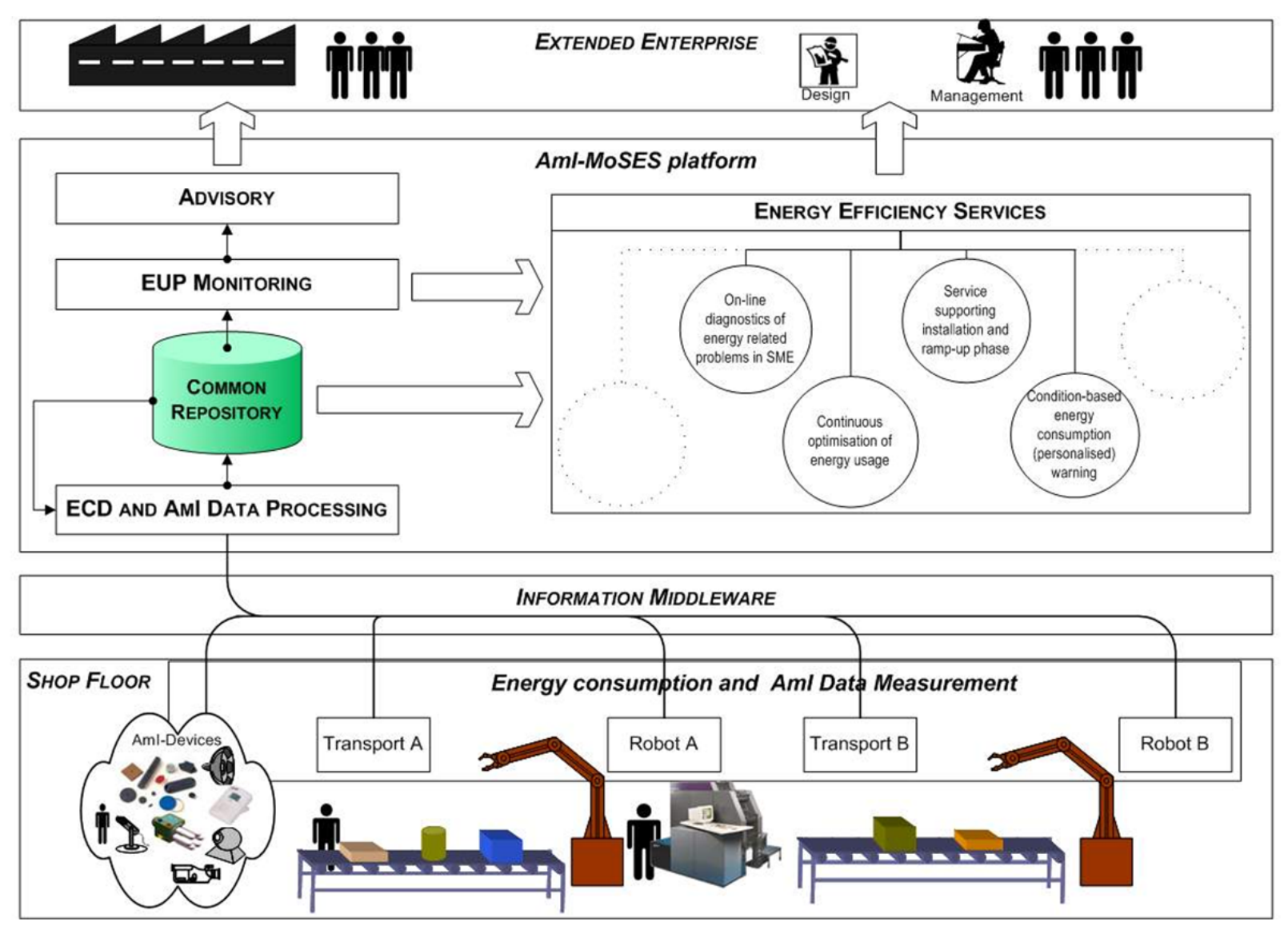

Figure 1: General Concept

(EUP is Energy Use Parameters)

\section{Ambient Intelligence, AmI}

The process of extending AmI to industrial applications is described in Stokic et. Al. (2006) [9]. The concept of AmI provides a vision of the Information Society where the emphasis is on greater userfriendliness, more efficient service support, user-empowerment, and support for human interactions' [10]. In a manufacturing domain, AmI includes a number of different aspects and technologies. The key issue is that it provides more effective monitoring and enables control of processes using sensors and sophisticated ways of extracting knowledge from them. Other definitions of AmI incorporate ambient intelligence as "the effective and transparent support to the activity of subject(s) through the use of information and communication technologies" [11].

Ambient Intelligence can be thought of as a system that incorporates the assessment and manipulation of the surrounding environment to provide effective support to the human personnel operating within it [12]. Therefore, the environment in which a Human Operator acts, includes both:

$\square$ Physical environment - for example a room with its physical features: temperature, humidity, lights etc. or manufacturing process with for example assembly line, and

$\square$ Contextual environment - for example the purpose of Human Operator actions, business processes, situation dependence etc.

Furthermore a further differentiation of ambience can be introduced:

$\square$ Manufacturing process related ambience, covering all planning and control processes of a general manufacturing system (plant, shop-floor, machine, device levels etc.). This "process ambience" also covers all classical product lifecycles.

$\square$ A wider human operator environment, not directly but indirectly related to the explicit manufacturing process, such as building, illumination, atmosphere etc.

The last two ambience dimensions may have physical as well as contextual features. 
A reference model for AmI in industry is presented here. This model is intended to support the communication process between people involved in a process, and information flow between a human operator and ambience. It ensures common, unified, unambiguous and understandable terminology among the people about the behaviour of devices or processes, and experts in different technical domains, realising a specific functionality of the devices to achieve the required behaviour.

An AmI System may have different functionalities [13]. It may:

$\square$ be an observer which provides increased knowledge (on human operator, process, environment) and intelligence to control or for information systems.

also include information or knowledge provision. For example, by providing information in more adequate way (for example provision of Diagnostics results in more effective way, via multi-media etc.).

provide higher level communication between a human operator and the system (for example, the system may allow for easier commands by the human operator based on context awareness and intelligence etc.).

The AmI features identified were adapted to the specific target of the systems described in this paper with improved monitoring of energy use. Examples of adapted AmI Features are in Table 1: AmI features, related AmI technologies and information which they could 'provide'. These features can be used to structure information for improved monitoring of energy use in manufacturing systems.

AmI features are expressed in a form that is understandable by a non-expert and possess the following characteristics. They:

- are technology independent,

- indicate the functional and/or non-functional requirement(s) relevant for the user, and

- correspond to one or more SPECIFIC characteristics of AmI.

Grouping the AmI features represented an approach to bridge the gap between the identification of processes to be improved, to identifying the required AmI potentials and the AmI technology required. The proposed classification represents a structure which is open for further extensions or refinements. 


\begin{tabular}{|c|c|c|}
\hline Aml features & $\begin{array}{l}\text { Related technologies \& functions of } \\
\text { supporting applications }\end{array}$ & $\begin{array}{l}\text { Potentially useful information for energy efficiency } \\
\text { optimisation (examples) }\end{array}$ \\
\hline $\begin{array}{l}\text { Explicit inputs from Human Operators } \\
\square \text { Natural inputs: spoken language, handwriting, } \\
\text { touch screen, gesture. } \\
\square \text { Observations and experiences about the status and } \\
\text { problems in process and environment. } \\
\square \text { Requests for data without knowing specific file } \\
\text { names, location or format. } \\
\square \text { Forwarding unstructured communication needs } \\
\text { with collaborating partners. } \\
\square \text { Inputs during collaborative work. }\end{array}$ & $\begin{array}{l}\square \text { Digital pen, handwriting and speech recognition. } \\
\square \text { Wireless handheld devices - PDAs, tablet PC or mobile } \\
\text { phones. } \\
\square \text { Wearable input devices: key boards, in-cloth, data glove etc. } \\
\square \text { Biometric authentication and authorisation. } \\
\square \text { Mobile communication and interoperability technologies } \\
\text { (Bluetooth, WLAN, GPRS, UMTS etc). } \\
\square \text { Collaborative working environment - core services. } \\
\square \text { Network interoperability and ubiquitous communication. }\end{array}$ & $\begin{array}{l}\square \text { Aml provides detailed information on human operator interaction } \\
\text { with the processes. This information can be used (together with } \\
\text { data on energy use) to identify how human operator behaviours and } \\
\text { interaction with the machines, equipment etc. may influence energy } \\
\text { use, for example standby of machines, level of machine utilisation, } \\
\text { etc. Establishing the energy use patterns in correlation to human } \\
\text { operator behaviour. } \\
\text { Analyses of suggestions, proposals from human beings that are } \\
\text { related to Energy Efficiency. }\end{array}$ \\
\hline $\begin{array}{l}\text { Explicit outputs of the Aml system } \\
\square \text { Information provision: delivery of personalised, } \\
\text { context-dependent content. } \\
\square \text { Active user assistance by for example proposing } \\
\text { most common/ appropriate answers. } \\
\square \text { User-friendly multimodal interfaces: } \\
\text { visual, voice user interfaces. } \\
\square \text { Communication with collaborating partners. }\end{array}$ & $\begin{array}{l}\square \text { Wireless handheld devices like PDAs, tablet PC. } \\
\square \text { Wearable output devices like head-set, head mounted } \\
\text { displays, see through displays, displays sewed in cloth. } \\
\square \text { Optical/acoustic output devices (light, pointers, horn). } \\
\square \text { Visual infrastructure equipment (TV monitors). } \\
\square \text { Network interoperability and ubiquitous communication } \\
\text { (WLAN, GPRS, UMTS technologies). }\end{array}$ & $\begin{array}{l}\text { These features also provide information to identify correlation } \\
\text { between the human operator behaviour and interaction with the } \\
\text { processes and energy use in these processes. } \\
\square \text { Information may be used to analyse how intelligent interaction } \\
\text { from Aml to human operators may support energy efficiency, for } \\
\text { example by providing information in an intelligent way to influence } \\
\text { behaviour and support energy optimisation. } \\
\square \text { Information/knowledge for energy optimisation. }\end{array}$ \\
\hline $\begin{array}{l}\text { Environmental inputs to the AmI system } \\
\square \text { Information from sensors/sensor networks on } \\
\text { basic environmental conditions (temperature, } \\
\text { humidity, vibration etc.). } \\
\square \text { Information on spatial situation and constraints in } \\
\text { respect to the human activity. } \\
\square \text { Information on hazardous (critical) changes in } \\
\text { the environment. }\end{array}$ & $\begin{array}{l}\square \text { Wireless networks of basic ambient sensors (temperature, } \\
\text { humidity, vibration). } \\
\square \text { Localisation and identification of "things" by camera systems for } \\
\text { spatial surveillance and detection of changes. } \\
\square \text { Network interoperability and ubiquitous communication } \\
\text { (WLAN, GPRS, UMTS technologies). }\end{array}$ & $\begin{array}{l}\square \text { Basic information for Energy } \\
\text { Efficiency Services. } \\
\square \text { Information can be used to analyse the influence of various factors } \\
\text { upon energy use and establish use patterns in correlation to } \\
\text { external factors. } \\
\square \text { Information on correlation between the external ambience factors } \\
\text { and human behaviour and interaction with the processes which } \\
\text { may have influence on energy use. }\end{array}$ \\
\hline Aml system outputs to the environment & & $\begin{array}{l}\square \text { Information may be used to analyse how changes made by Aml } \\
\text { systems influence energy use in processes. }\end{array}$ \\
\hline
\end{tabular}




\begin{tabular}{|c|c|c|}
\hline $\begin{array}{l}\text { Ambience - process inputs to the } \\
\text { Aml system } \\
\square \quad \text { Information about the status of process, plant, } \\
\text { machines, products and materials. } \\
\square \text { Information about the spatial structure of the } \\
\text { process plant. } \\
\square \text { Information on Location and movement of a device, } \\
\text { products and materials. }\end{array}$ & $\begin{array}{l}\square \text { Wireless networks of basic ambient sensors (temperature, } \\
\text { light, vibration of plant systems, machines and products. } \\
\square \text { Camera systems for spatial surveillance and detection of } \\
\text { changes to plant and products. } \\
\square \text { RFID tags (passive, active, smart tags), camera systems, } \\
\text { GPS etc. for location \& movement identification. } \\
\square \text { Data acquisition systems and processing of existing sensor } \\
\text { and process plant, machine and product data. } \\
\square \text { SOA for device communication targeting internet based Web } \\
\text { Services. } \\
\square \text { Network interoperability and ubiquitous communication } \\
\text { (WLAN, GPRS, UMTS technologies). }\end{array}$ & $\begin{array}{l}\square \text { Basic information for Energy Efficiency Services. } \\
\square \text { Information used to establish correlation between the processes } \\
\text { and energy use to establish a correlation between the energy use } \\
\text { patterns and process changes as well as correlation between } \\
\text { process and human behaviours and interaction which may influence } \\
\text { energy use. }\end{array}$ \\
\hline Aml system outputs to the ambience process & & $\begin{array}{l}\square \text { Information used to analyse how changes by Aml systems influence } \\
\text { energy use in processes. }\end{array}$ \\
\hline $\begin{array}{l}\text { Knowledge about ambience - environment/ } \\
\text { process and interaction }\end{array}$ & $\square$ Location Manager. & $\square$ Influence of process parameters upon energy consumption. \\
\hline
\end{tabular}




\begin{tabular}{|c|c|c|}
\hline Aml Features & $\begin{array}{l}\text { Related Technologies \& Functions of } \\
\text { Supporting Applications }\end{array}$ & $\begin{array}{l}\text { Potentially useful information for energy efficiency } \\
\text { optimisation (examples) }\end{array}$ \\
\hline $\begin{array}{l}\square \text { Knowledge about current and historical status of different } \\
\text { manufacturing system components, devices, products, } \\
\text { materials and users (machine, temperature and humidity } \\
\text { of environment, date/time and humans involved). } \\
\square \text { Knowledge about business process and energy efficiency } \\
\text { parameters. } \\
\square \text { Semantic correlation of user activity and process steps. }\end{array}$ & $\begin{array}{l}\square \text { Multi-agent technologies for the information/knowledge } \\
\text { processing in a distributed ICT environment based upon } \\
\text { user, ambience and system context. } \\
\square \text { Expert system technologies (RBR, CBR). } \\
\square \text { Peer-to-peer technologies. } \\
\square \text { Service-Oriented Architecture, semantic web } \\
\text { technologies, Web-Services, ontologies. } \\
\square \text { Network interoperability and ubiquitous communication } \\
\text { (WLAN, GPRS, UMTS technologies). }\end{array}$ & $\begin{array}{l}\square \text { Influence of environment upon energy consumption (for } \\
\text { diagnostics). } \\
\square \text { Historical/statistical data about problems reoccur- ring (for } \\
\text { continuous improvement). } \\
\square \text { Establishing correlations between energy use patterns and status } \\
\text { of different manufacturing systems components, and specifically } \\
\text { on interaction between humans and components. }\end{array}$ \\
\hline $\begin{array}{l}\text { Knowledge about context } \\
\square \text { Spatial configuration - combination of environment } \\
\text { parameters (layout and Aml) potentially leading to } \\
\text { excessive energy use or hazardous situations. } \\
\square \text { Process parameters configuration - combination of ECD } \\
\text { and Aml parameters - potentially leading to excessive } \\
\text { energy use or hazardous situations. } \\
\square \text { Similarity of contexts in different plants. } \\
\square \text { Influence of supporting ICT/ legacy systems on } \\
\text { energy efficiency. } \\
\square \text { Influence of different context components to context } \\
\text { precision. } \\
\square \text { User oriented relevant service creation in a given } \\
\text { environment or situation (Context- Aware service } \\
\text { discovery and provision). } \\
\square \text { Generating feedback by comparing current operations } \\
\text { (tracking tool status) with past experience, enabling } \\
\text { problem prevention and optimal experience generation. } \\
\square \text { Activity oriented collaboration among humans and devices. }\end{array}$ & $\begin{array}{l}\square \text { Multi-agent technologies for } \\
\text { the information/knowledge in a distributed ICT environment } \\
\text { based upon user, ambience and system context. } \\
\square \text { Rule based reasoning (RBR) and case based reasoning } \\
\text { (CBR). } \\
\square \text { Business Rules definition schemes. } \\
\square \text { Encapsulated interoperable \& autonomous system } \\
\text { components for monitoring, data exchange and/or } \\
\text { administration. } \\
\square \text { Expert systems. } \\
\square \text { Intelligent Interface Agents (Open Agent Architecture, } \\
\text { Distributed Agent Markup Language and the semantic } \\
\text { web) undertakes an information filtering role based up- on } \\
\text { perceived user interest. } \\
\square \text { Service-Oriented Architecture, semantic web } \\
\text { technologies, Web-Services, ontologies, smart devices. } \\
\square \text { Intelligent collaboration plat- forms. } \\
\square \text { Peer-to-peer technologies. } \\
\square \text { Knowledge base. } \\
\square \text { Network interoperability and ubiquitous communication } \\
\text { (WLAN, GPRS, UMTS technologies). } \\
\square \text { Collaboration services. }\end{array}$ & $\begin{array}{l}\square \text { Context knowledge for precise definition of conditions under which } \\
\text { specific energy consumption pattern occurs and for EUPs } \\
\text { definition. } \\
\square \text { Support correlation between energy use patterns and con- text. } \\
\text { Allows for comparison of energy use patterns in various plants and } \\
\text { benchmarking (allowing for energy use optimisation based on the } \\
\text { experience of others). }\end{array}$ \\
\hline
\end{tabular}


AmI systems were used to provide context aware monitoring of energy use in manufacturing systems. Unlike traditional monitoring systems, AmI systems provided not only raw/pre-processed data, but also knowledge on environment-ambience and process-ambiance. The basic assumption was that a system to optimise energy use could effectively deploy AmI information from measurements used in processes and from additional sensors integrated in the manufacturing environment, so-called AmI nodes. AmI nodes could also be existing knowledge repositories in companies. Sensors were the basic source of AmI information.

Examples of sensors used in energy use monitoring were: temperature, pressure, flow, frequency, speed, position and electrical energy consumption.

Transfer of sensor information into AmI information was achieved by combining single sensor information in a data collector or concentrator; initial information or data fusion was applied. Such combined sensor information sets were context components, that is AmI information. AmI data filtering occurred at two levels: at the sensor level and at the level of the AmI information.

Information from a single source was structured in the data collector and concentrator. Composed information was structured in a Common Repository. Structuring facilitated searching of the data base for data, information or knowledge components for the execution of EE services. Structuring aimed at mapping AmI information to existing knowledge components, that is the mapping of 'AmI information space' into an 'energy use management problem space'. This mapping required applying and correlating existing knowledge and knowledge tapped from other sources.

\section{Case Study - Mooring Chain Manufacturing}

The production of mooring chains $(\varnothing 60-210 \mathrm{~mm})$ includes a number of processes which are energy consuming. The production process starts with bar cutting and preheating, bending, welding, trimming, and pressing, ending with thermal treatment in the Double Quenching and Tempering (DQT) furnace (see Figure 2). In such a complex production process there are many parameters influencing energy efficiency.

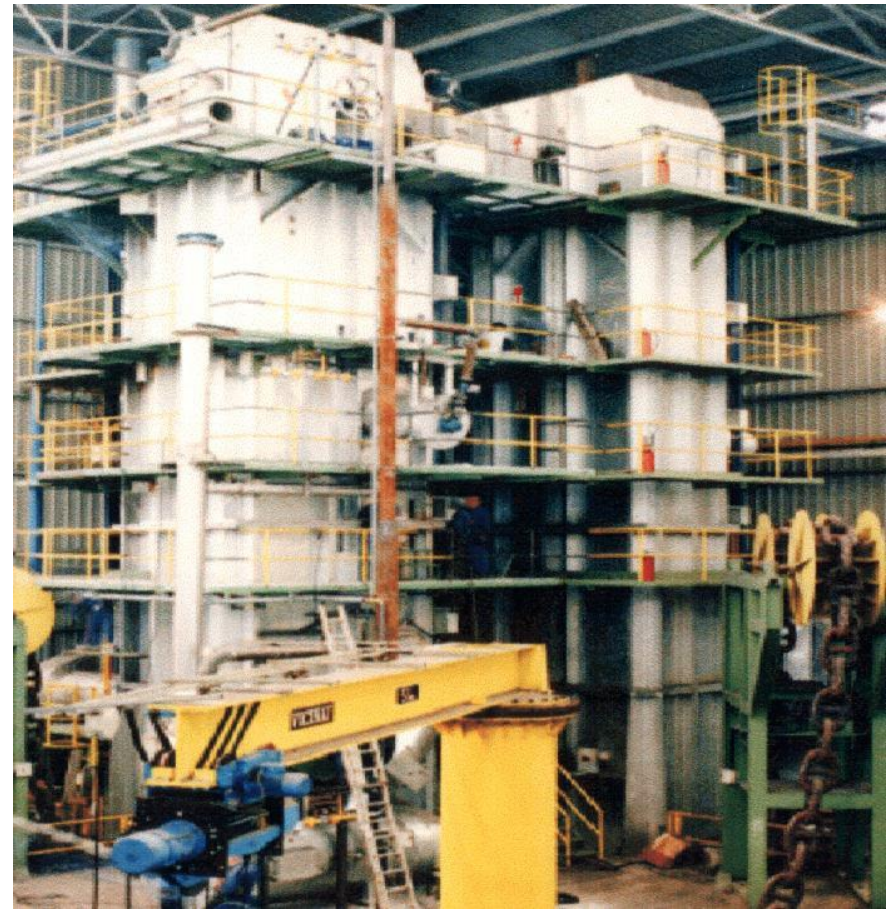

Figure 2: Vicinay Double Quenching and Tempering (DQT) furnace

In addition to strict energy consumption monitoring, gas consumption and electricity consumption, there were a number of other parameters, not directly related to the energy 
consumption but that were influential. In several cases there were measuring instruments used for controlling process parameters which were not directly related to energy efficiency. Establishing relationships among all these parameters, targeting an innovative, intelligent approach and system for energy efficiency was an important task for this company.

The company was also eager to fulfil the commitments to become an environmentally friendly enterprise and to get Eco-labelling certification (Green Label).

The source of energy in DQT was natural gas and its consumption in $\mathrm{m} 3$ was used for energy consumption control. Other process-related measurements were 18 fixed point temperatures within the furnace (used for control of the 3 burners' aperture), and velocity of the chain, which depended on the diameter of the link. Additional parameters to be taken into account by definition of the EUPs were temperature of the furnace insulation layer (cladding) and furnace environment temperature which could result in short-term energy efficiency increasing and a number of stop-start cycles during the production process to be used for increasing long-term energy efficiency.

\section{Transforming AmI information into knowledge}

“Ambient Intelligence Data" was "data enriched with and used within context", and transforming AmI information into knowledge involved the creation of knowledge pieces - chunks of different sensor data structured into a specific context framework [14].

The transforming process involved the following steps, as illustrated in Figure 3:

Smart distributed measuring of process data and human intervention in the manufacturing system was provided by AmI Systems integrated in those systems and in the physical environment. Using "AmI data adapter and filter" services, data from the shop-floor was collected and combined. This combination of information from different sources (sensors, machines and human interaction) provided knowledge about the system as a whole (process + human operator + environment).

- Processing and enhancing of information acquired from the manufacturing system assumed that:

○ models of the system were available. These models were defined as context models relevant to the manufacturing system. As the AmI system was distributed, these models had to be shared between components.

- Even if data-acquisition was distributed, AmI information was combined and processed in a central module (Knowledge generator or 'AmI context core'). Processing of AmI information implies: Context-reasoning, comprising context creation and context extraction: through reasoning via rule engines and/or by identification of temporal patterns in AmI sensor data.

Sharing and storage of information: after it had been processed, AmI information was organized and stored in a repository, so it could be accessed by the system services. 


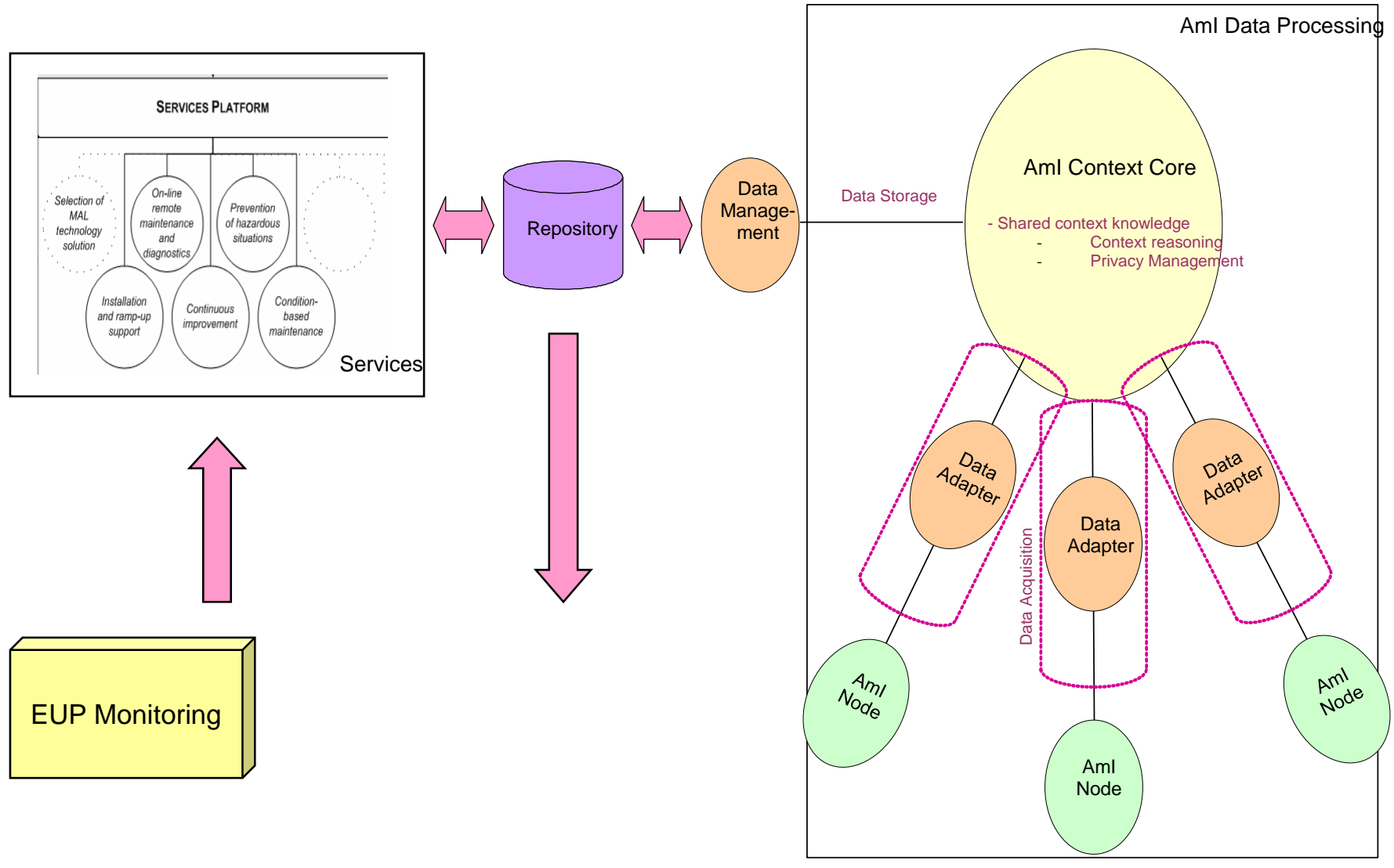

Figure 3: Transferring Aml Data into Knowledge

The process of transforming AmI information into knowledge within the Knowledge Generator unit involved the identification of temporal patterns in AmI sensor data, and saving it in the knowledge repository. Temporal Patterns were defined as "Informative correlations between the activities, both across time and sensors". The temporal patterns or sequences of data were identified based on the recurrence of stable usage patterns, such as knowledge coming from the repository. Once saved, temporal patterns could be used to predict future events by finding similar sensor sequences.

\section{Context modelling and definition of Energy Use Parameters (EUPs)}

Context can be seen as a set of data and parameters [15], which are not directly participating in the EUP formulas but that describe in detail the conditions under which a specific EUP calculation is valid. Plant, process and product models, and their relationships, as well as data on current production programmes, manufacturing systems configurations, and other application specific data were considered to be context related data. The context related parameters comprised of both AmI based information, either as measured values related to each other by rules (if the temperature X, for the manufacturing system life cycle period $\mathrm{Y}$ is higher than... then use the formula $\mathrm{A}$ for EUP"Z") or as a "chunk" of knowledge (for worker C at machine D multiply working time by...), and other process parameters (furnace zone temperature, process pressure etc.). In the system, the Core Services for Knowledge Management relied on a combination of object-oriented, logic based and ontology based models [16] and employed Rule-based and Case-based Reasoning techniques to extract knowledge from the given context. Specifically, rule-based reasoning was used to derive the current status of energy use of a manufacturing system, that is to assess a EUP's value with regard to energy use within a given context. Case-based reasoning was the main technique used during problem solving, when finding and comparing similar states.

Important parameters were the context aware Energy Use Parameters, which related monitored Energy Consumption Data (ECD) with AmI data. The EUPs related energy consumption parameters to consumption context which included ambient temperature, product types, equipment 
drive factors, process parameters, production conditions, equipment utilisation, amount of products produced, operating hours, equipment state and operator interactions with energy consumption data. Examples of EUPs are provided to illustrate ways of deploying them in the Energy Efficiency optimisation process.

Energy efficiency monitoring meant measuring energy consumption data and continually revisiting the measurements to identify consumption patterns [17]. It enables identification of improvement actions to decrease energy consumption. That was facilitated by monitoring energy consumption data and context data. The term Energy Use Parameter refers to a combination of different metric functions derived from measured data to identify the energy consumption within a specific context and to allow for the effective management of energy use. EUP can be the key energy performance parameter, indicator and index. EUP models were context aware. They took into account not only energy use but also the conditions under which energy was used and they facilitated the transformation of the measured and other data into knowledge for decision support. EUPs were used for monitoring energy efficiency but also for prognosis and trend analysis. Advice was based on monitoring results, state detection, the health assessment of the system based on current EUPs, prognosis or trends of EUPs, and results in decision support for the users. Advisory forms were based on High-level overviews of EUPs and a detailed drill-down view of the data behind the EUPs. The former were intended to help an energy manager to see the big picture and were meant to provide a general indication of energy use performance, whereby the latter worked in harmony with high level overviews of EUPs, providing additional details (context) about the background of data behind the EUPs. These details could help users understand why energy consumption exceeded limits for example.

\section{Energy Use Parameters Models}

Energy Use Parameters (EUP) models were application specific but generally observed EUP components were:

$\square$ Energy consumption data. The amount of energy used (for example kWh and/or kVA) and the energy costs (for example $£ / \mathrm{kWh}$ and/or $£ / \mathrm{kVA}$ ).

Process output in different units such as mass units, number of products, quality of services etc.

Energy consumption conditions - context - which impacted on the energy consumption, coming from different ambient, environment and process measurement, such as on specific process or environment temperature, type of product, medium pressure, operating hours, equipment state (off-time, uptime, idle, actual operating time) and operator interactions and other parameters which were measurable and could be correlated with energy consumption directly or indirectly.

The context components coming from different AmI sources provided more detailed, relational information, and thus also fundaments to knowledge about events when energy was consumed. An example of the factors influencing heat treatment process is shown in Figure 4. 


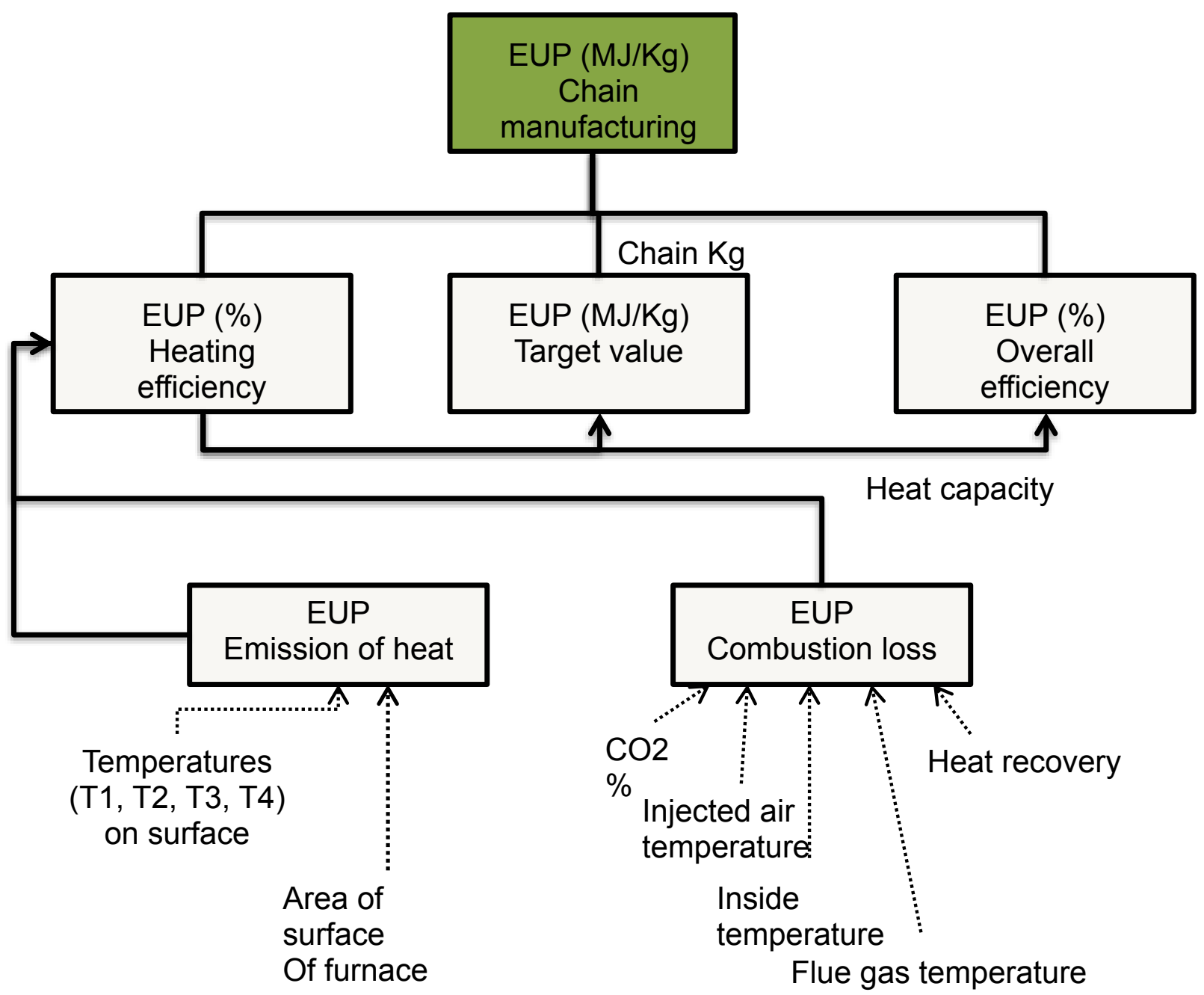

Figure 4: Factors influencing energy efficiency in the heat treatment process

\section{ICT System}

The concept of a generic system is presented in Figure 5 below.

As it can be seen in Figure 5, the system comprised the following modules:

ECD and AmI data Processing Module, presented as Information Middleware

Service platform with the following groups of services:

- Generic Core Services: for Management of Social Interactions, related to the collaborative activities; KM services, comprising reasoning related services, and knowledge provision services

- Application Specific Core Services: for EUP definition, calculation and monitoring, services for problem solving, and services for Context, modelling and extraction/reasoning

- Energy Efficiency Services: core services and application specific software tools for specific applications and including services for condition based warning, Online Problem Diagnostics, support to installation and ramp-up and support to continuous improvement of energy efficiency in manufacturing systems.

General Run-time Infrastructure, comprising Service Execution Environment, Security Services and External Systems Integration Services. 


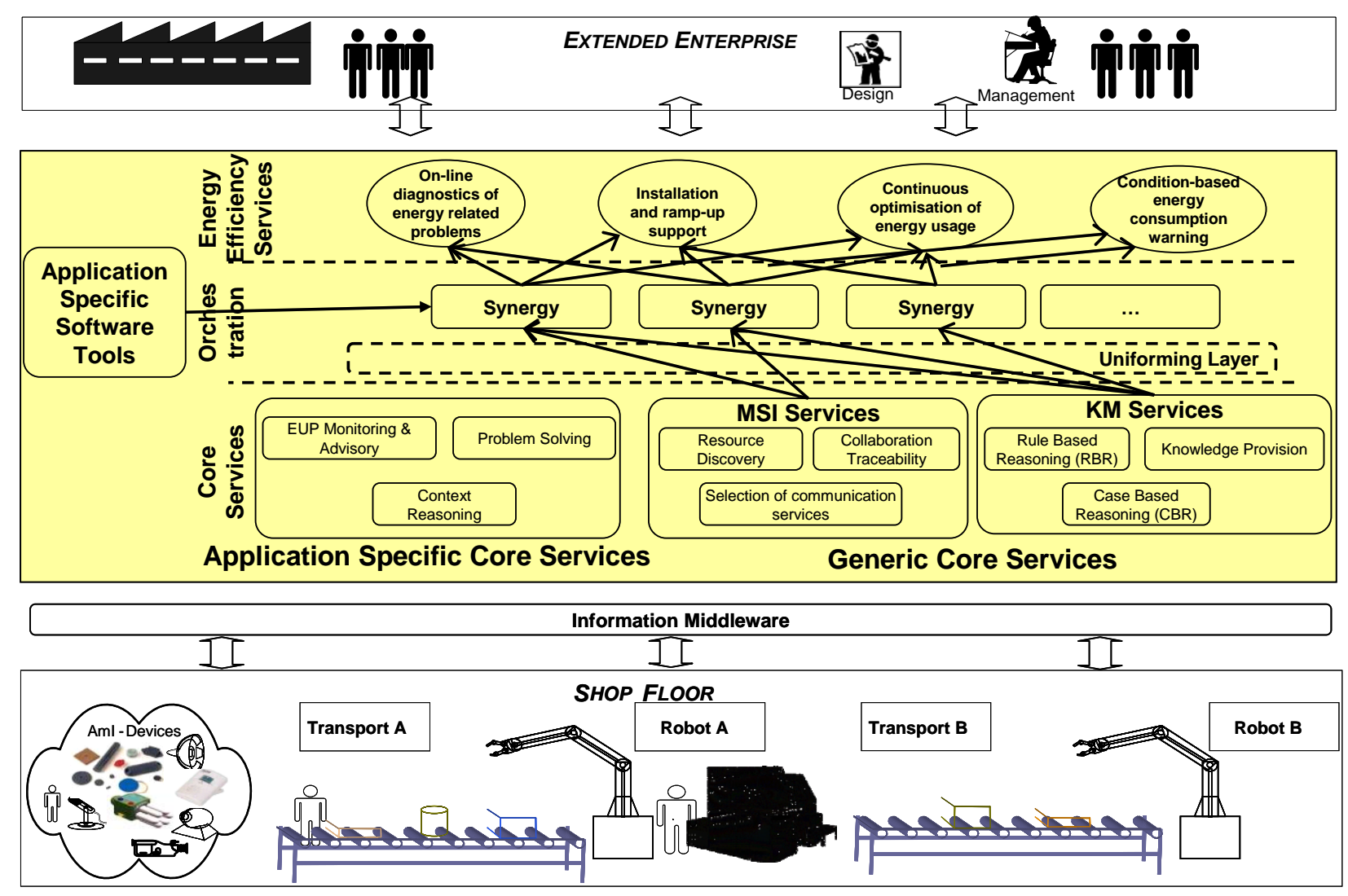

Figure 5: Developed System Concept

Table 2 provides an overview of these components indicating their key purpose, short description and key problems solved.

Table 2: Overview of key modules

\begin{tabular}{|c|c|c|c|}
\hline Module & Purpose & Description & Key problems \\
\hline $\begin{array}{l}\text { ECD and Aml data } \\
\text { Processing Module } \\
\text { - Information } \\
\text { Middleware. }\end{array}$ & $\begin{array}{l}\text { Process information from } \\
\text { different Aml systems } \\
\text { (environment- ambiance } \\
\text { and process- ambiance) to } \\
\text { support calculation of EUP } \\
\text { and different services. }\end{array}$ & $\begin{array}{l}\text { Combines ECD information from MS with Aml data to } \\
\text { provide high level information for EUP monitoring. }\end{array}$ & $\begin{array}{l}\text { Adding context to the ECD and } \\
\text { information from Aml systems. } \\
\text { Collecting information from } \\
\text { manufacturing systems. }\end{array}$ \\
\hline $\begin{array}{l}\text { Service platform } \\
\text { with two groups of } \\
\text { services: } \\
\text { - } \quad \text { Generic Core } \\
\text { - Services } \\
\text { - Application } \\
\text { Specific Core } \\
\text { Services } \\
\text { - Energy } \\
\text { Efficiency } \\
\text { Services. }\end{array}$ & $\begin{array}{l}\text { Provide services to optimise } \\
\text { Energy Efficiency along the } \\
\text { manufacturing system life- } \\
\text { cycle. }\end{array}$ & $\begin{array}{l}\text { Generic Core Services: } \\
\text { - } \quad \text { Management of Social Interactions and KM } \\
\text { Services. } \\
\text { Application Specific Core Services: } \\
\text { - } \quad \text { EUP Monitoring and Advisory, Context Reasoning } \\
\text { and Problem Solving. } \\
\text { Energy Efficiency services: } \\
\text { - Condition-based energy consumption warning } \\
\text { - } \quad \text { On-line diagnostics of energy related problems } \\
\text { - } \quad \text { Cervice supporting installation and ramp-up phase } \\
\text { Continuous improvement of energy efficiency. }\end{array}$ & $\begin{array}{l}\text { Defining flexible EUP models } \\
\text { and EUP prediction models. } \\
\text { Comparing the predicted and } \\
\text { actual values and effectively } \\
\text { updating models. } \\
\text { Using actual and predicted } \\
\text { EUP and providing information } \\
\text { for EUP. }\end{array}$ \\
\hline $\begin{array}{l}\text { General Run-time } \\
\text { Infrastructure. }\end{array}$ & $\begin{array}{l}\text { To provide Run-time } \\
\text { conditions for reliable } \\
\text { system functioning. }\end{array}$ & $\begin{array}{l}\text { Standard Services for assuring safe and reliable } \\
\text { functionalities, such as Execution Environment, Security } \\
\text { Services and Services for integration of external } \\
\text { systems. }\end{array}$ & $\begin{array}{l}\text { Assuring interoperability } \\
\text { conditions for different services } \\
\text { within the common Execution } \\
\text { Environment as well as } \\
\text { providing appropriate access } \\
\text { rights for users in an Extended } \\
\text { Enterprise. }\end{array}$ \\
\hline $\begin{array}{l}\text { Common } \\
\text { Repository. }\end{array}$ & $\begin{array}{l}\text { Central repository gathering } \\
\text { data for all modules. }\end{array}$ & $\begin{array}{l}\text { Collection of Knowledge on product / processes for } \\
\text { computation / prediction of EUP, and creation of } \\
\text { services, of rules and cases for RBR and CBR } \\
\text { respectively. }\end{array}$ & $\begin{array}{l}\text { Application in distributed } \\
\text { Extended Enterprise. }\end{array}$ \\
\hline
\end{tabular}




\section{Energy Consumption Data and Aml Data gathering and pre-processing}

ECD and AmI data were gathered using two types of components, as shown in Figure 6: Data Concentrator and Data Logger to connect the system platform with an arbitrary number of sensors. Each data concentrator can either manage other data concentrators or the connected data collectors. Standard low-power microcontroller units, completed hardware components such as realtime- clocks, backup batteries, graphical displays and even a temperature sensor that could detect the temperature of the data logging station were used for the data gathering assemblies. With these hardware components the system platform received detailed data such as appearance of possible critical states (power-loss, storage loss...). The Data collector units had different kinds of communication interfaces (Ethernet, serial bus, PLC or wireless) and could be attached to existing communication lines. All gathered ECD and AmI data in general was configurable, where the user could decide, which information was important for analysis and evaluation, whereby the preprocessing of the measured data was done within the data collector. Both ECD and AmI data were observed as outputs from sensors/meters spread in the manufacturing process, configured according to existing requirements. The Data Concentrator requested or received collected and pre-processed data from data collectors and transmitted to the system platform and stored in a database (by communicating with a web service). It was important to optimise the amount of communication events and transmitted data with data collectors and system platform. The data concentrator included the functionality to filter, verify and compress collected data.

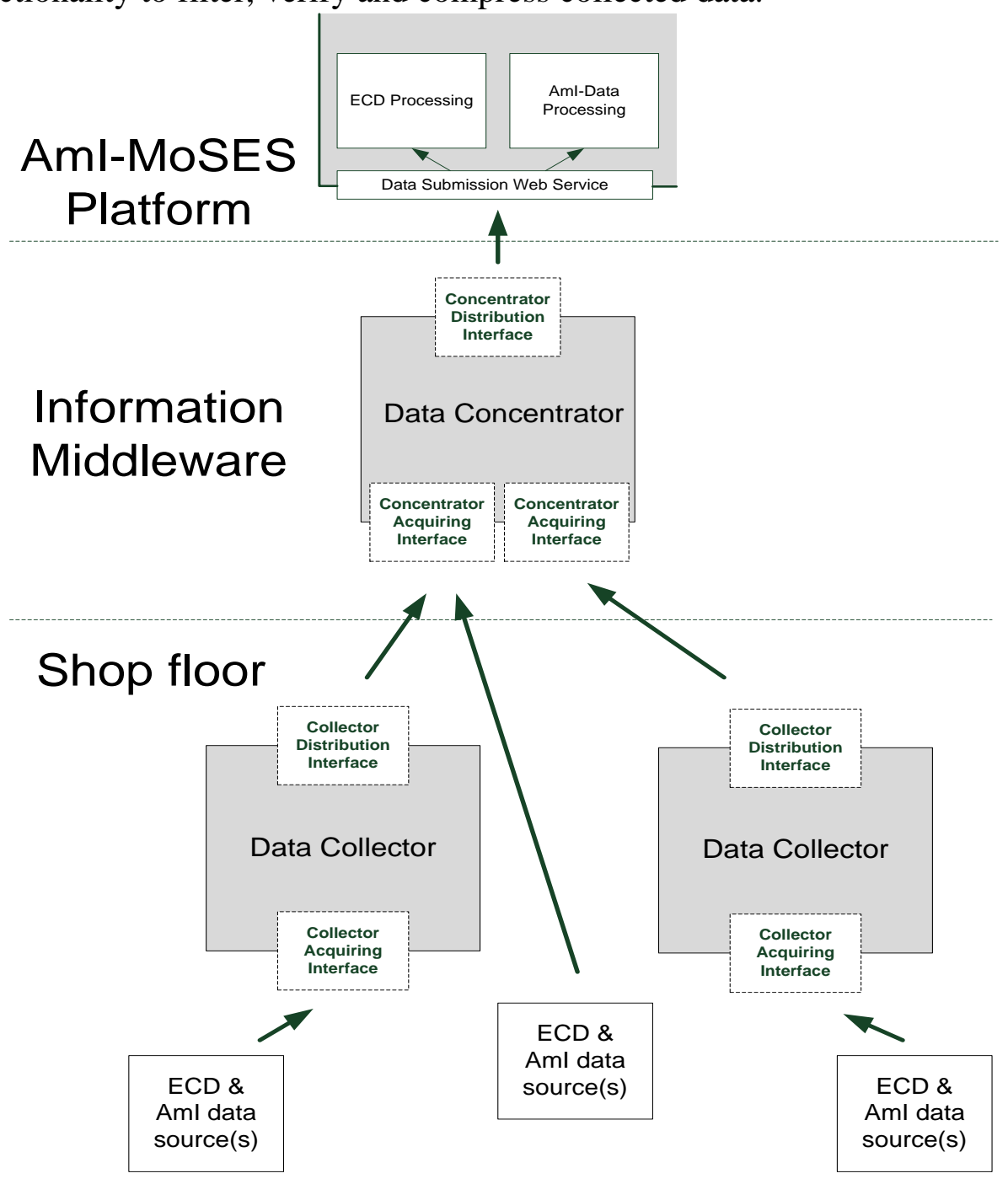

Figure 6: Basic architecture for one Data Concentrator connected to many Data Collectors 
Data collectors and concentrators included memory for storing collected data in case of data transfer problems (when GSM network failed or Ethernet cable was damaged). It was also possible to integrate two separate storage capabilities: internal and external Flash/EEPROM memory cells as well as $\mathrm{SD} / \mu \mathrm{SD} / \mathrm{MMC}$-Card Interfaces to allow records of measurement data if the system had down-time.

\section{Platform description}

Based on Service Oriented Architecture (SOA) principles, the platform allowed the combining of different core software services.

Decision support was realised by applying reasoning mechanisms on data coming from energy consumption measurement and AmI parameters measurement.

SOA platform was aimed at:

acquisition of information needed to optimise energy use in Manufacturing Systems over the life cycle, using this information for:

$\circ$ derivation of Life-cycle related Energy Use Parameters and decision support to optimise energy use, and

○ provision of an open set of energy efficiency services for optimal energy use in manufacturing systems in different life-cycle phases.

\section{Generic Core Services}

The Management of Social Interactions (MSI) Service for Resource Discovery was used to find experts possessing predefined expertise within an Extended Enterprise, whereby the search criteria, related to the specific expertise and the availability was selected from a set defined in the common repository. MSI Service for Selection of Communication Services had a search criteria defined as the personal communication preference within the available communication means or company policies regarding communication, such as telephone or email communication. Collaboration Tracking \& Tracing Service kept track of user actions performed on the platform. Its functionality included recording and storing user activities in the Common Knowledge Repository as well as retrieving tracked activities from the Knowledge Repository. The result was a list of tracked activities recorded during the work on solving a particular energy efficiency problem. Each line of the table listed the activity type, when it was performed and by whom. Contact details of the user who performed the activity could also be seen. The Tracking \& Tracing search results could be filtered by event type and/or user who performed the activity using dropdown boxes. Notification Service provided functionality for informing defined responsible staff member(s) about important events regarding energy efficiency, using existing communication means and taking into account the staff members' communication preferences. In the case of an alarm about an energy efficiency problem, the notification service would send notifications to the staff members defined in the alarm definition. For each alarm, several recipients could be selected. One or more notification methods for the alarm could be defined using checkboxes for EMAIL, SMS and PLATFORM.

The KM Service for Case-based Reasoning (CBR) used the free software JColibri. The CBR core service itself was used in the Service platform directly as a part of the problem solving Application Specific Core Service and indirectly in the Energy Efficiency services for Online Diagnostics, Ramp-up support and Continuous Improvements. Essential functionalities of a Case Based Reasoning system were a comparison of "cases" (predefined patterns and calculation of similarities), which were applied for comparison of a new problem description with a set of descriptions of previously solved problems, saved in Knowledge Repository, and in discovering similar cases. As a result of the comparison, a list of solved problems with corresponding similarity with a new problem was issued. For the problem description, several predefined Graphical User Interfaces (GUIs) were applied, including context data. Total similarity was calculated as a sum of weighted particular criteria whereby the criteria weights could be allocated for each specific application case 
with values in the range 0 to $100 \%$. Output of this functionality, possible problem causes, and proposed actions were shown. Instead of selecting a cause from a similar problem, a user with sufficient rights may also define a new cause and attach new actions to that cause. KM Service for Rule-based reasoning whose basic Rule Based Reasoning (RBR) principle can be described as execution of "if" - "then" infers on a rule-base, which contained all of the appropriate knowledge encoded into If-Then rules. In the system this reasoning functionality was applied in context reasoning by the EUP monitoring system and in the service for condition-based warning. The process steps were as follows:

When a new value came into the system, the RBR component checked whether the corresponding EUP for which the value was being saved was a part of an existing rule. If this was true the value was evaluated against the set thresholds in the corresponding rules.

There were two types of RBR checks. First the normal check that evaluated the current value whereas the second type predicted future values, it estimated the trend of future values based on several past values. How the second evaluation type was calculated depended on the prediction method set on the EUP. Both of these checks raised an alarm if the thresholds were breached. The alarm for the prediction type check were there to prevent abnormal or erroneous future conditions and was used for condition based maintenance service. The first type of the alarm was raised when these abnormal or erroneous conditions were already in place. In the ramp up phase it was expected that more error alarms would be raised. But with continuous usage more of the prediction alarms were expected since more knowledge was stored in the system and the user obtained more detailed knowledge on how to fine tune "if-then" rules. The "if-then" rules were applied using mathematical operands $\langle\rangle,,=$ and their combinations. There could be more than one EUP in one rule and the rules could be a combination of target and context rules. Rules could take into account the target values in a certain context. The KM Service for Knowledge Provision provided functionalities for uploading, storing and retrieving information resources from the platform Common Repository or if the information was not directly available in the Common Repository the system interfaced existing legacy systems and tried to retrieve information that did not conflict in order to assist the users in solving energy related problems.

The Data Management Services were decomposed into the following components:

- Data Manager: a generic service that offered basic data management functionality to store (create), update and delete an entity, as well as retrieve an entity specified by its ID or all entities of a given class.

- Specific Data Managers: to perform complex data queries according to defined criteria.

\section{Sub-system for Measurement and AmI Data Processing and EUP Management}

The Measurement and AmI Data Processing and EUP Management sub-system had three main parts, the:

Measurement Data Processing module provided a web service interface for importing measurement data from Energy Consumption Data and AmI parameter measurement devices or other data sources into the platform. This module processed the incoming data to build context out of and around the measured data to allow for a high- resolution picture of current energy use.

$\square$ EUP Definition module provided a user interface for configuring Energy Use Parameters and Energy Consumption Data / AmI Data variables.

EUP Monitoring and Advisory module provided a user interface for monitoring EUP and measurement data values, for producing report documents and for exporting the data to spread sheet tools. In addition, this module contained components for extrapolating EUP values to allow for prognosis when a EUP might leave the predefined value range, (to advise users on possible incoming problems).

The measurement data manager implemented a web service interface that allowed client software or 
intelligent devices to post measurement data into the platform. The measurement data was stored into the database and all dependent EUPs were re-evaluated. An event was sent to notify the energy efficiency services of the presence of new data, which was then checked for any warning conditions or other causes for action.

The EUP Definition module was used for configuring the handling of both measured data and the corresponding EUPs. This module typically used in the initial set-up phase before measurements were started, but changes to the configuration could be made in real time on a running system.

The EUP monitoring and advisory module was used for gathering data about energy usage. It allowed a user to gain a quick overview of the current state of the system, and provided numeric and graphical output about the history of the data. Reports could be generated in various document formats or previewed online as web pages. The raw data could be exported into Excel or CSV files for further analysis in external tools.

\section{Knowledge Repository}

The Knowledge repository was a relational database. Access to the database from the platform's services was through a standard Java Persistence API interface provided by the JBoss Hibernate library. The entity object code used by all services was created automatically from a graphical UML diagram design by using the AndroMDA framework for model driven architecture. By using a common object-oriented data model on the platform's side, the used database server (currently MySQL) could be replaced by any major relational database servers.

The complete structure of the Knowledge repository was created early in the research and populated with data for early testing. However, the structure of the KR was deliberately left open for possible adaptations, which were expected to appear during early testing and complete implementation.

\section{EUP Model definition}

The EUP Model definition module was activated from the corresponding GUI and important components for EUP model setting such as definition of measuring devices, measurements (ECD and AmI Data), energy use parameters and targeting models were inserted. Each of these parameters had a list of existing entries. The links for each existing entry allowed a user to edit or delete the existing entries. Measurement data were data streams that were produced by measurement devices connected to the system. The editing view for measurement data allowed the user to give the variables a context by selecting a production unit, a process step and / or a product part to which the variable was related. New EUP variables could be created by applying a mathematical operation to existing variables or constant values. Constants could be created directly in the EUP editor view. Targeting models were used for setting conditions on variables. The monitoring module checked these conditions and showed any violations to the user. Targeting models included a set of conditions that determined when the model was to be applied (context) and a set of conditions that determined the value ranges that triggered the condition. The first set of conditions defined which value ranges were tolerable for the selected EUPs under the context defined by the second set of conditions, under which the target model was to be evaluated. For example for which product part the model was defined or which ambient data measurements were to be taken into account. For both measurement data and EUPs one could select a "Prediction Method", which was to forecast the development of values into the future using mathematical models. The forecasted values for measurement data and EUPs could also be evaluated by the targeting models to predict excessive energy use before it occurred. 


\section{Condition based Warnings}

Condition based warnings alerted users of unacceptable deviations from normal energy consumption. The condition based warnings applied different KM mechanisms to measured values or calculated EUPs. Preconditions for appropriate functions:

$\square$ Step 1: In a set-up phase the platform - knowledge repository - was filled with knowledge about the involved manufacturing systems and processes as well as the energy consumption measurement devices and AmI devices available. The form and frequency of gathering data from these devices was defined and EUP models were set up to compute current or estimate future energy use. Corresponding rules were defined to specify allowed ranges of context aware EUPs.

Step 2: During the manufacturing system runtime phase energy use was constantly monitored by computing current and estimating future values for the defined EUP models using measured energy consumption and AmI data. The computed/estimated values were matched against the rules specified in step 1, using rule-based reasoning to try to detect any excessive use of energy.

$\square$ Step 3: If the EUP Monitoring and Advisory Module detected an excessive use of energy or the trends of estimated values indicated a future occurrence of such an unacceptable use - i.e. the computed/calculated EUP values violated any of the rules specified in step 1 - a warning was issued to notify responsible users and information about the detected problem is stored in the common repository. Alternatively, a user might detect an energy related problem by observing measured energy use. In this case, he could insert the problem related data manually.

Condition based warnings issued different notifications depending on the way the alarm was set up. After opening the alarms GUI the table with all alarms was shown to the user, offering three possibilities to process the pending alarm.

The user could cancel the alarm in two different ways:

confirm an alarm, meaning that the alarm would be removed from the alarms table, or choose the Start problem solving button.

The latter button confirmed an alarm and, in addition, redirected the user to a problem solving service. This service enabled management of alarms saved in the system knowledge repository. The alarms could be either Delete by deleting the saved alarm definition in which case the entry was removed from the table, Edit it or Show history for the alarm definition. Show history opened a window where a table with every alarm occurrence was listed.

Functionality Edit allowed problem updating by editing an alarm in the saved alarm definitions or defined a new alarm. Alarm data GUI was structured in five main sections:

General data about the alarm: name, description, if alarm is active.

Alarm recipient management, where new recipients can be added or existing recipients removed.

EUP targets, where users could choose an existing EUP target that had been set up in the EUP Targeting portion of the EUP Definition part of the system or set up a new EUP target.

$\square$ Probable causes for the alarm, where the main difference with the Service for On-line Diagnostic of Energy related Problems became relevant. This difference was that for an energy related event that breached pre-set threshold values where the probable cause was most likely known, the On-line Diagnostic of Energy related Problems was not launched since the probable cause was already known.

Alarm details section; to inform staff about which equipment raised the alarm.

\section{On-line Diagnostics}


This service provided diagnostics support by identifying problems in energy use (for example a sudden peak in energy consumption) and quickly, "almost real-time" provided cause(s) and action(s) to eliminate a problem. Problems were detected from information provided by energy consumption measurement systems, AmI systems and human operators. By monitoring EUPs, the Energy Efficiency problems were identified and possible causes offered (as described in the section about the Condition based warning service). For diagnosing problems with unknown causes the service for On-line Diagnostics was launched. The collected information about the problem was saved in the knowledge repository. The service compared the new case with cases already stored as solved problems, applying Case Based Reasoning mechanisms and delivering a list of possible problem causes, sorted according to the problem-similarity-level with previously solved problem cases. Knowledge about causes and actions related to problems already solved provided valuable support in solving the problem and identifying causes of the problem. After having selected one as supposedly correct, the user could get support in solving it in the form of a list of activities. Additionally, the user(s) might request help in solving the problem from other (external) experts; (for example manufacturing system vendors). In such a case the service would support collaboration of internal and external users, actors within Extended Enterprise, to solve the problem by using the functionality to search for appropriate experts and provide contact information, etc.

\section{Installation and Ramp-up Support}

Installation and Ramp-up Support was intended to help users with diagnosing energy-related problems in a manufacturing system during the installation and ramp-up process of new plants, in a similar way to the Service for On-line Diagnostics of Energy related Problems. Ramp-up Support relied on the same functionality as the on-line diagnostics service. In the process of new equipment installation and ramp-up then problems could occur and at the same time a limited amount of knowledge was available about the installation. The case base of solved problems as used in the service for on-line diagnostics did not exist. The user could use the "Find Expert Help" functionality. As a result of a request, a user was presented with a list of available maintenance experts possessing the necessary expertise to provide support in solving his problem. In addition to general contact information for each expert; e-mail address, phone number, etc.. The list also indicated if the expert was currently online. In case the expert happened to be online an additional link "Request support" was available. The contacted expert received the notification on their screen and could directly access the on-line diagnostics service to search for a solution.

\section{Continuous Improvement of Energy Efficiency}

Continuous Improvement of Energy Efficiency enabled plant experts to detect increases in the number of problems associated with the same problem type [18]. The detection was provided either automatically by the system, or "manually", based on standard quality control procedures and practices within the organisation. In the former case, the plant expert adjusted configuration parameters for the automatic detection of increasing problems, such as the frequency of a problem, problem type, occurrence, notification type and addressees etc. Problems reoccurring more often than prescribed were analysed by a plant expert with the aim of discovering innovative solutions for the improvement of the processes and product parts involved in these problems. These solutions and proposals were compiled in the form of 'suggestions' and sent as feedback to design staff. The application of these suggestions was expected to reduce the frequency of such problems. To prevent the problem from occurring so frequently, a process step or some of its associated product parts or production units may have to be redesigned. A precondition for the application of this Energy Efficiency Service was that the database of problems should contain a critical mass of content with attached actions, that is to say, the problems should be marked as solved via the On-line Diagnostics of Energy related Problems Energy Efficiency Service. Depending on the approach followed for the enabling application (manual or automatic), the service provided two appropriate menu items. In both cases the case base was checked and the solutions most often applied to the recurring problems were analysed and sent to the design department. 


\section{Case Study Results}

The AmI-MoSES platform prototype was applied to the heat treatment of manufactured chains. This operation, together with flash butt welding, is one of the key processes in chain manufacturing in terms of assuring high product quality. Treatment in the Double Quenching and Tempering furnace ensured that every link gave a metallurgical response that fell within very tight margins.

The monitored EUP in this case was consumed energy per kilogram of manufactured chain, in context of (a) chain size and chain speed, (b) furnace surface (cladding) and environment temperature, and (c) number of stop-start cycles.

The manufacturing of chains and other components for mooring systems was energy intensive, and was the cause of ever increasing costs. The company needed to radically reduce these costs to maintain its competitive position in the world market. The company intended to innovate its manufacturing processes with AmI solutions. They introduced wearable context aware terminals for maintenance personal (developed in the scope of a local project). Special emphasis was put on safety aspects where application of smart tags was one of the approaches to be applied. The problems were how to use the information obtained by such solutions to optimise energy use in the manufacturing process and provide better energy efficiency services. The AmI-MoSES system was connected with a set of new sensors and smart tags and man-machine interfaces (including the wearable terminals for maintenance staff), as well being connected to ambience sensors (HVAC systems on the shop-floor, presence of operators etc.) in order to collect information needed for EUP of manufacturing. Improvements in services for on-line diagnostics using this additional information was achieved. The case study showed that energy monitoring and using AmI technologies via the AmI-MoSES platform could reduce energy consumption and ensure acceptable process performance at the same time.

The developed platform will be the corner stone of the company's (Vicinay Cadenas S.A.) energyefficiency projects. Progress has been made to give rise to several internal sub-projects. These subprojects deal with machine diagnostics in that they enable predictions to be made regarding the "health" of the chain manufacturing equipment. The knowledge-based reasoning and diagnostic features of the platform will form an integral part of new systems.

\section{Conclusions}

This paper presented the results from the research work into optimising energy savings whilst at the same time ensuring manufacturing productivity using context aware ambient intelligent technologies. The chain manufacturing case study demonstrate the effectiveness of the approach. This work could be further developed by applying the technologies at the design stage, when designing the manufacturing processes by adding the sensor networks and the required software ontology to the process design. The aim is to enhance existing product/process design systems with features that will enable engineers to collaboratively design energy efficient and ecologically optimal discrete manufacturing processes, and generate appropriate extended monitoring and decision making services to support manufacturing installations to ensure optimal ecological impact over the process life cycle. Industrial companies have invested resources to make their products as energy efficient as possible. There is a lack of ICT systems/tools to support product/process design for energy efficiency of installations. A critical issue in energy use optimisation of manufacturing processes is availability of knowledge on actual energy consumption patterns within such processes. Ambient Intelligent (AmI) systems integrated in manufacturing installations may support energy efficiency of processes through extended services and provide such knowledge to optimise process design from energy efficiency point of view. It is clear that new ICT approaches can bring significant benefits to manufacturing sectors, including efficiency and sustainability. 


\section{References:}

[1] O. Starzer, (1999). Effective Tools for Industrial Energy Efficiency - SAVE Conference in Graz, Austria, 1999.

[2] DA Sanders and A Gegov, (2006). Ambient Intelligence. Jnl of computing in syst' \& eng', 7 (1), pp $78-82$.

[3] L. Snidaro; GL. Foresti, (2007), Knowledge representation for ambient security, Expert Systems 24, Pages: 321-333.

[4] D. Stokic, R. Neves-Silva, M. Marques, (2007). Ambient Intelligence System for life-cycle management of complex manufacturing and assembly lines, 2007 IEEE International Conference on Industrial Informatics (INDIN), pp 945-950

[5] M. Coles, D. Azzi, BP. Haynes, (2008). A Self-healing Mobile Wireless Sensor Network Using Predictive Reasoning. Sensor Review, Vol 28, Number 4, Pages 326-333.

[6] S. Scholze, H. Sundmaeker, U. Kirchhoff, (2008). Ambient intelligence Technologies for Industrial Environments in Manufacturing SME's. ICE 2008, 14th Int Conf on Concurrent Enterprising; Costa Caparica, Portugal, pp 71-78.

[7] DA. Sanders, (2008). Environmental sensors and networks of sensors. Sensor Review 28 (4), pp $273-274$.

[8] D A Sanders, H Liu, DJ Harrison and A Gegov. (2008) Energy Efficiency based on Ambient Intelligence. Journal of computing in systems and engineering, 9 (1), pp $114-120$. 2008. ISSN 1472-9083.

[9] D. Stokic, U. Kirchhoff,. H. Sundmaeker, (2006). Ambient Intelligence in Manufacturing Industry: Control System Point of View, The 8th IASTED Conference on Control and Applications, CA, Montreal, May 2006.

[10] D A Sanders, H Liu and DJ Harrison, (2008). Distributed user interfaces for ambient intelligent environments. Journal of Intelligent Mobility, 11 (3), pp 158 - 167. 2008. ISSN 1472-7633

[11] S. Kopacsi, G. Kovacs, A. Anufriev, (2007). Ambient Intelligence as enabling technology for modern business paradigms, Robotics and Computer-Integrated Manufacturing, Volume: 23 Issue: 2 Pages: 242-256

[12] IST Advisory Group Report (2004): Experience and Application Research: Involving Users in the Development of Ambient Intelligence; EU-Report 09/2004.

[13] G. Riva, F. Vatalaro, F. Davide \& M. Alcañiz (Eds.), (2005). Ambient Intelligence in Practice: Future Perspectives and Applications. IOS Press, 2005, pp.237-264.

[14] A.K. Dey, (2001). Understanding and Using Context, Personal and Ubiquitous Computing, Volume 5, Number 1 / February 2001. 
[15] M. Bazire, P. Brézillon, (2005). Understanding Context Before Using It. In: Modelling and Using Context: 5thInternational and Interdisciplinary Conference CONTEXT 2005, Paris, France, July 5-8, 2005, Springer, 35-54.

[16] A. Schmidt, (2006). Ontology-based User Context Management: The Challenges of Dynamics and Imperfection. In: Proceedings of the International Conference on Ontologies, Databases and Applications of Semantics (ODBASE 2006).

[17] R. Tavenard et al., (2007). Searching for Temporal Patterns in AmI Sensor Data, European Conference on Ambient Intelligence (AmI'07), Darmstadt, Germany, November 2007.

[18] D A Sanders, (2007). Intelligent ambient software to optimize energy and power systems, Journal of computing in systems and engineering, 8 (2). pp 110 - 112. 2007. ISSN 1472-9083.

\section{Reserve References}

[33] Haerder, T. and Reuter, A. (2009) "Principles of Transaction-Oriented Database Recovery”. ACM Computing Surveys (ACSUR) 15 (4): pp. 287-317.

[36] Ducatel K. et al. ISTAG Scenarios for Ambient Intelligence in 2010. Final Report, IPTSSeville, February 2010. European Commission.

[5] E. Aarts, S. Marzano, The New Everyday: Views on Ambient Intelligence, 010 Publishers, 2003

[7] Ambient Intelligence E4 SME project. Revolution in Industrial Environments - Euro' Commission IST Prog' (05-08). Finding new technological \& organisational approaches to enable SMEs to use ambient intelligence technology for systemic innovation.

[8] D.A. Sanders, CR Smart, A Gegov and B Gremont. A prototype ambient intelligence sensor network based on a computer and a radio transceiver. Journal of Intelligent Mobility, 10 (1), pp 136 - 138. 2007. ISSN 1472-7633

[12] EU report: Wireless tags- Prospects \& Obstacles, 2003

[14] H. Liu, N. Kobota; Special Issue - Robotics for Ambient Intelligence, Int' Jnl of Robotics \& Automation, In press.

[16] SK. Gill, K. Cormican, Support ambient intelligence solutions for small to medium size enterprises: Typologies and taxonomies for developers. Paper @ 12th Int Conf on Concurrent Enterprising, ICE 2006, Milan.

[29] M. Coles, D. Azzi, BP. Haynes and A. Hewitt; A Bayesian Network Approach to a Biologically Inspired Motion Strategy for Mobile Wireless Sensor Networks" Elsevier's Ad hoc networks Journal. In press - (2009).

[30] DA Sanders, GE Tewkesbury, DC Robinson (2011). Simple expert systems to improve an ultrasonic sensor-system for a tele-operated mobile-robot. Sensor Review: international journal of sensing. 
